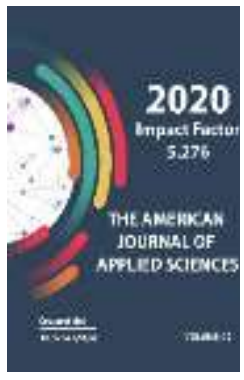

Journal Website: http://usajournalshub.c om/index,php/tajas

Copyright: Original content from this work may be used under the terms of the creative commons attributes 4.0 licence.

\section{The Change In The Concentration Of Phospholipids In Experimental Infection Of Lambs With Echinococcosis And Paecilomyces}

\author{
Vakhidova Adolat Mamatkulovna \\ Candidate Of Biological Sciences, Associate Professor Of The Department Of Microbiology, \\ Virology And Immunology Of Sammi, Uzbekistan
}

\section{Oripova Pokiza Alimovna}

Candidate Of Biological Sciences, Assistant Of The Department Of Microbiology, Virology And Immunology Of Sammi, Uzbekistan

\author{
Bobokhandova Mehriniso Fazliddinovna \\ Assistant, Department Of Microbiology, Virology And Immunology Sammi, Uzbekistan \\ Boltaev Komil Sultanovich \\ Assistant, Department Of Microbiology, Virology And Immunology Sammi, Uzbekistan
}

\title{
ABSTRACT
}

Mechanisms of action on tissues caused by helminths are known to lead to atrophic changes. Especially sharp atrophy is observed in echinococcosis. At the same time, along with mechanical destruction and compression ischemia of tissues adjacent to the bodies of helminths, irreversible necrobiotic or necrotic changes occur due to toxic effects on the host body. At the same time with mechanical damage to tissues disturbed by helminthiasis, productive and inflammatory phenomena occur, leading to the growth and neoplasm of tissue elements, as in echinococcosis. The General complex of pathomorphological changes in helminthiasis is currently regarded as a manifestation of allergies and immune suppression. In this connection, there is an almost important question about the mechanisms of formation of manifestations of helminthiasis in the form of specific syndromes that determine the correctness of their diagnosis. These syndromes and their changes in the dynamics of the disease are based on typical pathological processes (dystrophy, local circulatory disorders, myocarditis, inflammation, allergies, immune deficits, etc.).

\section{KEYWORDS}

Pecilomycosis, lambs, cenurosis, cardiopathy leucoformula, phospholipids. 


\section{INTRODUCTION}

Complication of echinococcosis of paecilomyces has become an acute problem in surgery and veterinary medicine. The term "complication of echinococcosis of paecilomyces", the aim of this work to study the concentration of phospholipids in experimental echinococcosis.

\section{MATERIALS AND METHODS OF RESEARCH}

Under the experiment were taken 35 lambs that were infected with Echinococcus eggs taken from donor dogs, 5 lambs-cenurosis, 5cysticercosis Ovis, 5-alveococcosis, 5pecilomycosis, infected with material from patients and 5 lambs made up the control group. Before infection, the lambs were counted three times pulse, respiratory movements, blood tests (leucoformula and ESR), determination of hemoglobin, sugar, phospholipids, protein and immunoglobulins. Then the same studies were conducted every other day, on the 5th day, and every 10 days. The lambs received 5,000 units of eggs inside. The eggs were asked once. Control and infected ones are distributed according to the principle of analogues.

\section{RESULTS AND METHODS}

In this report, the development of infectioustoxic cardiopathy and myocarditis (ITCM) at the first stages of infection is of interest. Similar observations were made in Pediatrics, when children developed pecilomycosis at an early age, such observations are not available among animals.

We first established the following results. Lambs who received antibiotics for a long time and did not take antifungal drugs were ill, there were cardiac symptoms, rapid fatigue, decreased motor activity, shortness of breath. There were toxic symptoms of heart failure. The overall condition of the infected lambs was more severe compared to the control ones. After a single infection with helminth eggs, large-focal lymphocyte infiltrates formed in the myocardium of the heart, and later fibroblast proliferation occurred. Later it was found pronounced changes in the cardiomyocytes of the myocardium, characterized by swelling and fragmentation of myofibrils. Significant destructive changes were found in the mitochondria, they were manifested by the destruction of the outer membrane, disorganization of the Crist. This explains the increase in phospholipids in the initial stage of the disease. However, after a month, structural changes in cardiomyocytes became less pronounced, which indicates compensatory functions of the body. On the part of General clinical indicators, persistent anemia was observed, in the leukocyte formula, along with monocytosis, lymphocytosis and eosinophilia was observed, ESR within the normal range. As for the biochemical parameters, the total serum phospholipids were significantly increased in infected lambs, compared to control ones. Studying the dynamics of the picture of the protein composition of blood in echinococcosis, pecilomycosis, cysticercosis, alveococcosis, we found that the first contact of invasive helminth larvae and fungal spheres of pecilomycetes to the host tissues caused changes in the spectrum of blood proteins. The decrease in total protein was due to albumins and gamma globulins, which indicates the suppression of protective humoral factors. In the future, a significant decrease was found and a return to the original level. This is due to the mobilization of non-specific gamma 
globulins, and with the growth of parasites, suppression occurs. Repeated increase is associated with the formation of specific gamma globulins.

Cytotoxins, which are products of tissue breakdown and cause the development of autoallergia, play a great role in the development of the pathological process in heart tissues with helminthiasis.

\section{CONCLUSIONS}

These observations allow us to conclude that in many helminthiasis complicated by pecilomycosis, morphological changes develop in the heart muscle of animals regardless of the migration path of larvae and the localization of helminths. The morphological picture in the heart during invasion is non-specific and serves as a manifestation of allergic myocarditis, accompanied by alterations, necrosis of vascular walls and myofibrils, eosinophilic infiltration of tissue and degeneration of cardiomyocytes. The degree of myocardial damage significantly affects the severity of clinical manifestations and the outcome of diseases.

\section{REFERENCE}

1. Berezhko V. K., Sasikova M. R., Haidarova A. A. Study of the immunotherapy effect of the immunomodulator Roncoleukin in secondary alveolar echinococcosis//Theory and practice of fighting parasitic diseases. 2016. no. 17. Pp. 58-61.

2. Kokolova L. M., Platonov T. A., Verkhovtseva L. A. Role of parasitic diseases in human pathology/l Yakut Medical Journal. 2008. no. 3 (23). Pp. 47-50.

3. Kostrykina T. V., Dmitrieva G. M., Sorokina O. V., Tikhonova E. P., Maslennikova N. A. the Epidemiological situation of echinococcosis in the Krasnoyarsk territory and the organization of dispensary monitoring of patients with echinococcosis / / Infection and immunity. 2017. No. S. S. 867

4. Sultanova R. S., Medzhidov R. T., Medzhidov Sh. R., Khamidov T. M. Causes of recurrent abdominal echinococcosis and its prevention// Astrakhan medical journal. 2016. Vol. 11, No. 3. Pp. 125-130.

5. Khestanova M. S., Khestanova E. A., Kertanov S. R. To the question of determining the species belonging of pathogens of certain helminthiasis in North Ossetia-Alania // Young scientist. 2019. No. 29 (267). Pp. 34-36.

6. Yarmukhamedova S. Kh., Vakhidova a.m., Ismoilova M. sh., Amirova sh. a. Structural and functional heart disorders at different stages of chronic heart failure in patients with postinfarction cardiosclerosis and dilated cardiomyopathy // Modern technologies: problems of innovative development, Kemerovo, 2019, p. 268-272.

7. Sakamoto, Tsukasa; Gutierrez et al. Pulmonary complications of cystic echinococcosis in children in Uruguay // Pathology International. - 2005. - Vol.50, №3. - P. 497-503.

8. Tabrizi F., Englund A., Rosenqvist M. et al. Influence of left bundle-branch block on long -term mort alive in a population with heart failure// Eur Heart J. - 2007. -28. P.2449-2455. 